Article

\title{
Influence of Bovine Serum Albumin (BSA) on the Tribocorrosion Behaviour of a Low Carbon CoCrMo Alloy in Simulated Body Fluids
}

\author{
Choshun Yoneyama, Shoufan Cao, Anna Igual Munoz * and Stefano Mischler \\ Tribology and Interface Chemistry Group (SCI-STI-SM), Ecole Polytechnique Fédérale de Lausanne (EPFL), \\ Station 12, CH-1015 Lausanne, Switzerland; choshun.yoneyama@epfl.ch (C.Y.); shoufan.cao@epfl.ch (S.C.); \\ stefano.mischler@epfl.ch (S.M.) \\ * Correspondence: anna.igualmunoz@epfl.ch
}

Received: 22 April 2020; Accepted: 20 May 2020; Published: 25 May 2020

\begin{abstract}
Tribocorrosion, as the interaction between mechanical wear and electrochemical corrosion, has been found to be the main problem causing the failure and limiting the lifetime of metal-on-metal artificial hip joints. Better understanding of the tribocorrosion mechanisms of CoCrMo alloys is needed in order to reduce the degradation of this alloy, especially in the presence of proteins as one of the organic components present in synovial fluid. In this study, tribocorrosion tests of a low carbon CoCrMo alloy in phosphate buffer solution (PBS) with and without bovine serum albumin (BSA) in two different concentrations at different applied potentials (passive and cathodic) were carried out. The results show that the effect of proteins on wear and friction was concentration and potential dependent. In the cathodic domain (absence of very thin passive film), wear was very low in all solutions and the friction was significantly reduced by the addition of BSA to PBS even at low BSA concentrations. However, in the passive domain, the friction and wear were found not to be affected when the BSA concentration was $0.5 \mathrm{~g} / \mathrm{L}$, while they were reduced when increasing the BSA concentration to $36 \mathrm{~g} / \mathrm{L}$. The tribocorrosion results were rationalized through an existing tribocorrosion model and the effect of BSA on wear and friction was explained by the consideration of physical factors such as changes in viscosity and double layer structure, because in the present results no tribofilm formation was observed.
\end{abstract}

Keywords: tribocorrosion; bovine serum albumin; wear; friction; lubrication; CoCrMo

\section{Introduction}

CoCrMo alloys are wear- and corrosion-resistant materials commonly used in biomedical implants such as artificial knee and hip joints and dental devices. In such applications, these alloys are exposed to the combined action of wear and corrosion by the surrounding body fluids. This combined action is called tribocorrosion and results from the complex interaction of a variety of mechanisms, such as lubrication, loss and establishment of passivity, build up of surface chemical films, cold work hardening, dynamic recrystallization of strained material forming nanocrystalline layers in the near surface zone of the metal, mechanical mixing, and release of metal and oxidized particles [1]. The tribocorrosion of CoCrMo alloys has been extensively investigated by different researchers since 2000 and was reviewed in 2013 [2]. A robust predictive model was proposed by Cao et al. [3] based on wear, corrosion and hydrodynamic lubrication concepts.

The presence of proteins in synovial fluids is supposed to play a crucial role in the tribocorrosion of CoCrMo alloys used in hip implants. For example, Wimmer et al. [4] observed the buildup of carbonaceous films on the surface of CoCrMo hip joints after implantation in patients. This tribolayer 
was attributed to the reaction of denatured proteins with the metal surface and was thought to play a significant role in wear reduction of hip implant joints [5]. Albumin is the most abundant organic species in synovial fluid and, not surprisingly, its role in the tribocorrosion of CoCrMo alloys has been the object of a large number of investigations. In general, it was observed that adding albumin to a simulated body fluid tends to reduce wear and friction [6-10], although the extent of the effect varies depending on the simulated body fluid [8].

Only a few studies have analyzed mechanistically the effect of proteins on the tribocorrosion response of CoCrMo. Wang et al. [10] reported that adding albumin to a phosphate buffer solution (PBS) solution lead to the generation of a tribofilm in self-mated cylinder-on-flat CoCrMo contacts and a corresponding lowering of friction and wear. The formed tribofilm contained metal oxides and hydroxides as well as phosphates but no significant organic species. Moreover, these authors observed a much thicker nano-crystalline zone in the near surface zone of the contacting metal and, deeper, a larger subsurface deformation after sliding in the albumin solution compared to the PBS alone. They proposed two mechanisms to explain their observations: first, by adsorbing on the sliding surface albumin reduces friction, this prompts large strains to appear in the subsurface, thus leading to the buildup of the nano-crystalline layer and larger subsurface strain hardening that reinforces wear resistance. On the other hand, albumin promotes the formation of the hard tribofilm that mechanically protects the underlying surface and thus reduces wear. Note that these mechanisms do not imply the formation of surface carbonaceous layers (indeed no significant organic layer was reported by those authors).

Namus et al. [11] studied the effect of normal load on the friction, wear, subsurface transformation and carbonaceous layer formation on a CoCrMo alloy flat sliding against an alumina ball in calf serum solutions. The sliding velocity was $0.2 \mathrm{~m} / \mathrm{s}$, a relatively high value favoring (elasto)hydrodynamic lubrication. Indeed, very low coefficients of friction (COF), below 0.03 , were measured in all their tests. The wear coefficient was found to be slightly lower with increasing load to attain a minimum value for loads in the range 40 to $60 \mathrm{~N}$. Under those loading conditions, the wear tracks were found using Raman spectroscopy and optical microscopy, to be locally covered with a carbonaceous layer. Interestingly, these lower wear rates in the presence of a carbonaceous layer were found associated to a thinner nano-crystalline layer compared to the other loads. This is contrary to what was observed by Wang [10]. At $80 \mathrm{~N}$, no such layer was observed and a transition towards higher wear values took place.

Wimmer et al. [12] investigated the effect of incremental normal force in a similar range of values as Namus [11] but using a larger ceramic ball as counterpart to the CoCrMo flat yielding lower contact pressures. Their tests were carried out in a calf serum solution under applied electrode potential. These authors found a non linear increase in wear volume with the applied load with a leveling off in the range of 32 to $56 \mathrm{~N}$ that was attributed, based on the electrochemical measurements, to the formation of a surface tribofilm, the nature of which was not identified.

The results from literature discussed above are not sufficient to understand the mechanisms by which albumin affects the tribocorrosion behavior of CoCrMo alloys. However, they point out several crucial factors that should be considered as potentially relevant, such as frictional and normal stresses, possible buildup of tribofilms, (elasto)hydrodynamic lubrication, and subsurface transformations. The extent of the impact of these factors on the tribocorrosion mechanisms is also dependent on the investigated contact conditions. The complexity of the topic, essentially due to the interplay of the different factors, requires experiments carried out under well controlled mechanical and (electro)chemical conditions as well as mechanistic models (reviewed in [13]) allowing for quantitatively assessing the influence of well-defined parameters on the tribocorrosion of $\mathrm{CoCrMo}$ alloys in order to rationalize the experimental results. The aim of this work is to shed light on the role of BSA on the friction and wear behavior of a low carbon CoCrMo alloy under different electrochemical conditions. For this, bovine serum albumin (BSA) is employed as a model protein. Tribocorrosion wear and friction is evaluated by potentiostatic tribocorrosion tests carried out at different applied potentials in BSA solutions. Surface analysis including scanning electron microscopy (SEM) and Auger electron 
spectroscopy (AES) will be conducted, and the relation between surface modification effect and the lubrication effect of proteins will be discussed based on established models and concepts.

\section{Materials and Methods}

Wrought low carbon CoCrMo alloy samples (C: $0.05 \%$.wt, Cr: 28\%.wt, Mo: 6\%.wt, Co: $65.95 \%$.wt) in the form of discs $24 \mathrm{~mm}$ in diameter and $5 \mathrm{~mm}$ in thickness were used. Samples were ground with $\mathrm{SiC}$ sandpapers up to \#4000 in water, and polished with a diamond suspension with particle size of $1 / 4 \mu \mathrm{m}$. The resulting surface roughness (Sa) of the CoCrMo samples was $10 \mathrm{~nm}$, comparable to that of a commercial metal femoral head.

Polycrystalline alumina balls (Shanghai Unite Technology, Shangai, China) $6 \mathrm{~mm}$ in diameter were used as a counterpart material in the tribocorrosion tests. The disks and the balls were ultrasonically cleaned for $5 \mathrm{~min}$ in ethanol and acetone bath before each test.

A phosphate buffer solution (PBS) containing $0.14 \mathrm{M} \mathrm{NaCl}, 1 \mathrm{mM} \mathrm{KH}_{2} \mathrm{PO}_{4}, 3 \mathrm{mM} \mathrm{KCl}$ and $10 \mathrm{mM}$ $\mathrm{Na}_{2} \mathrm{HPO}_{4}$ was employed as the simulated body fluid. Additionally, two different amounts of bovine serum albumin (BSA) fraction V supplied by Merck were added to the PBS solutions, $0.5 \mathrm{~g} / \mathrm{L}$ (BSA $0.5 \mathrm{~g} / \mathrm{L}$ ) and $36 \mathrm{~g} / \mathrm{L} \mathrm{BSA}$ (BSA $36 \mathrm{~g} / \mathrm{L}$ ) to check the effect of protein concentration on the tribocorrosion response of the CoCrMo alloys.

The viscosity of all solutions (PBS, BSA $0.5 \mathrm{~g} / \mathrm{L}, \mathrm{BSA} 36 \mathrm{~g} / \mathrm{L}$ ) was measured using a concentric cylinder rheometer (Tain Instruments HR-3, New Castle, DE, US). Sheer rate was swept from 0.1/s to $1000 / \mathrm{s}$.

The corrosion behavior of the CoCrMo alloy was assessed by carrying out potentiodynamic curves in the different electrolytes in a three-electrode cell and a potentiostat (Autolab PGSTAT302, Herisau, Switzerland). An $\mathrm{Ag} / \mathrm{AgCl} 3 \mathrm{M}$ reference electrode ( $0.210 \mathrm{~V}$ versus standard hydrogen electrode) and a platinum wire counter electrode were used for the electrochemical tests. The exposed surface area of the CoCrMo alloy in the electrolyte was $254 \mathrm{~mm}^{2}$. The open circuit potential (OCP) of the alloy was measured for $600 \mathrm{~s}$ before the potentiodyanmic scan. Then, the potential was scanned from $-1.2 \mathrm{~V}_{\mathrm{Ag} / \mathrm{AgCl}}$ to $0.8 \mathrm{~V}_{\mathrm{Ag} / \mathrm{AgCl}}$, at a scan rate of $2 \mathrm{mV} / \mathrm{s}$. Tests were done under aerated conditions.

The passivation charge density of the CoCrMo alloy was determined by means of a potential step method. The test was conducted using the same three-electrode cell setting as previously described with a potentiostat (Bank elektronik Wenking LB 95L, Pohlheim, Germany). The samples were first polarized at a cathodic potential of $-1.5 \mathrm{~V}_{\mathrm{Ag} / \mathrm{AgCl}}$ for $30 \mathrm{~s}$ in order to remove the oxide film and then the potential was switched to the desired passive potential $\left(-0.2 \mathrm{~V}_{\mathrm{Ag} / \mathrm{AgCl}},-0.05 \mathrm{~V}_{\mathrm{Ag} / \mathrm{AgCl}}, 0.35 \mathrm{~V}_{\mathrm{Ag} / \mathrm{AgCl}}\right)$ while the current transients were recorded every $0.1 \mathrm{~ms}$. The passivation charge density was quantified by integrating the current density during the first $0.5 \mathrm{~s}$ of the polarization. Tests were repeated twice for checking reproducibility.

Tribocorrosion tests were carried out using a home-made reciprocating linear motion ball-on-disk tribometer which is combined with an integrated three-electrode electrochemical cell and a potentiostat (Bank elektronik Wenking LB 95L, Pohlheim, Germany) described elsewhere [14]. The normal load was $5.6 \mathrm{~N}$, the wear track length $5 \mathrm{~mm}$ and the sliding frequency $1 \mathrm{~Hz}$. A dwell time of $0.25 \mathrm{~s}$ was held after each stroke, resulting in a sliding velocity of $20 \mathrm{~mm} / \mathrm{s}$. The tribocorrosion test procedure consisted of measuring the OCP of the CoCrMo for $600 \mathrm{~s}$, applying a selected potential for another $600 \mathrm{~s}$, applying the load and starting the sliding for $1800 \mathrm{~s}$ while keeping the selected potential applied and finally, stopping the motion and keeping the applied potential for another $300 \mathrm{~s}$. During the tests, the response in current was registered simultaneously to the frictional force and the position of the pin holding the alumina counterpart. Four different applied potentials $\left(-1 \mathrm{~V}_{\mathrm{Ag} / \mathrm{AgCl}},-0.2 \mathrm{~V}_{\mathrm{Ag} / \mathrm{AgCl}},-0.05 \mathrm{~V}_{\mathrm{Ag} / \mathrm{AgCl}}\right.$, $\left.0.35 \mathrm{~V}_{\mathrm{Ag} / \mathrm{AgCl}}\right)$ were selected. One of them corresponded to the cathodic domain $\left(-1 \mathrm{~V}_{\mathrm{Ag} / \mathrm{AgCl}}\right)$ and the rest to different passive potentials. All corrosion and tribocorrosion tests were carried out at room temperature. Wear morphology was analyzed at the end of the tribocorrosion tests by optical and scanning electron microscopy, FE-SEM (Zeiss Merlin, Oberkochen, Germany). Quantification of the wear loss volume was determined by confocal microscopy (Keyence VK-X200, Itasca, IL, US) measuring 
the area below three different cross-sections of the wear track perpendicular to the sliding direction and multiplying by the length of the wear track.

After the tribological tests, the samples were cleaned by sonicating for $5 \mathrm{~min}$ in a pure ethanol bath and surface analysis inside and outside the wear tracks was carried out by Auger electron spectroscopy (AES) in a PHI 680 Scanning Auger Nanoprobe (Physical Electronics GmbH, Germany) using tilted angle of $0^{\circ}$ and an energy of $10 \mathrm{keV}(10 \mathrm{nA})$ electron-beam. The measurements were performed over an area of around $20 \mu \mathrm{m} \times 20 \mu \mathrm{m}$ by scanning the electron beam and integrating the signal. Depth profile acquisition was done by scanning at $1 \mathrm{keV}(500 \mathrm{nA}) \mathrm{Ar}+$ beam over an area of $1 \mathrm{~mm} \times 1 \mathrm{~mm}$. The sputter rate of $\mathrm{SiO}_{2}(1.47 \mathrm{~nm} / \mathrm{min})$ was used to estimate the sputtering depth from the sputtering time. Obtained signals were then converted to the atomic concentration ratio by using the PHI Multipak software, considering the peak-to-peak signal strength of each element in the derivative spectrum and the relative sensitivity factors taken from the database of the software. AES measurements were performed on 5 points for each condition to check the homogeneity of the surface.

AES depth profiles were corrected for the influence of the electron escape depth [15] already applied by Mischler et al. to passive films $[16,17]$. The electron inelastic mean-free paths (IMFP) were calculated according to the method proposed by Tanuma et al. [18] and the following values, in nanometers, were used: 0.76 for $\mathrm{C}, 1.14$ for $\mathrm{O}, 1.17$ for $\mathrm{Cr}, 1.53$ for $\mathrm{Co}, 0.67$ for Mo and 0.97 for $\mathrm{N}$.

\section{Results}

\subsection{Corrosion Behaviour}

Figure 1 shows the polarization curves of the CoCrMo alloy in the PBS solutions with different BSA contents. Three distinct domains typical to passive metal can be seen: cathodic domain, passive domain, and transpassive domain. The cathodic domain which is below $-0.6 \mathrm{~V}_{\mathrm{Ag} / \mathrm{AgCl}}$ is controlled by the water and dissolved oxygen reduction. The passive domain is characterized by the current plateau observed between $-0.4 \mathrm{~V}_{\mathrm{Ag} / \mathrm{AgCl}}$ and $0.4 \mathrm{~V}_{\mathrm{Ag} / \mathrm{AgCl}}$ in which the oxide film inhibits the anodic dissolution of alloy. The addition of BSA mainly affects the transition between the cathodic and the anodic domain by shifting the corrosion potential by about $0.1 \mathrm{~V}$ towards more cathodic values. These results are in good agreement with previous studies which attributed this cathodic shift in the corrosion potential to the nature of albumin as a cathodic inhibitor and anodic catalyst [19].

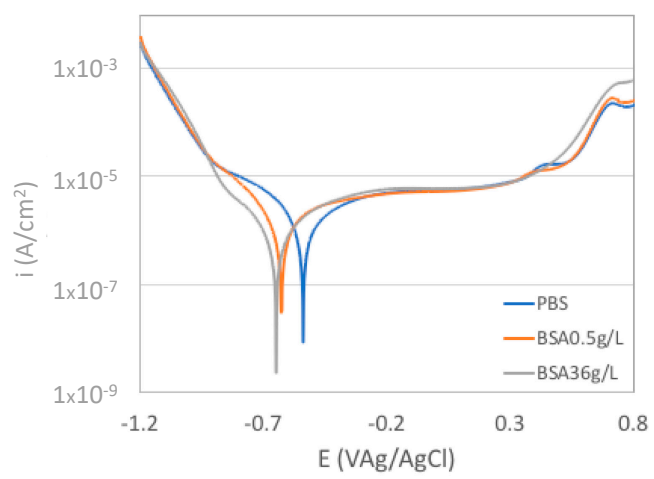

Figure 1. Polarization curves of the CoCrMo alloy in the phosphate buffer solution (PBS) solutions with different albumin concentration.

The transpassive domain above $0.4 \mathrm{~V}_{\mathrm{Ag} / \mathrm{AgCl}}$ is mainly controlled by the transpassive oxidation. The current shoulder observed at around $0.7 \mathrm{~V}_{\mathrm{Ag} / \mathrm{AgCl}}$ except in the $\mathrm{BSA} 36 \mathrm{~g} / \mathrm{L}$ solution has been previously observed in phosphate containing solutions and attributed to the formation of phosphate-chromium ion complexes [20]. 


\section{Passivation Charge Density}

Figure 2 shows the variation in the average values of the passivation charge density $\left(Q_{p}\right)$ at different applied potentials in all the studied solutions. It is possible to observe how $Q_{p}$ linearly increases with the potential following the same empirical equation (yellow line) as previously obtained by Bao et al. [21]. Those authors quantified $Q_{p}$ values in different electrolytes at different applied potentials and already observed that $Q_{p}$ depends linearly on the applied potential independently on the solution chemistry.

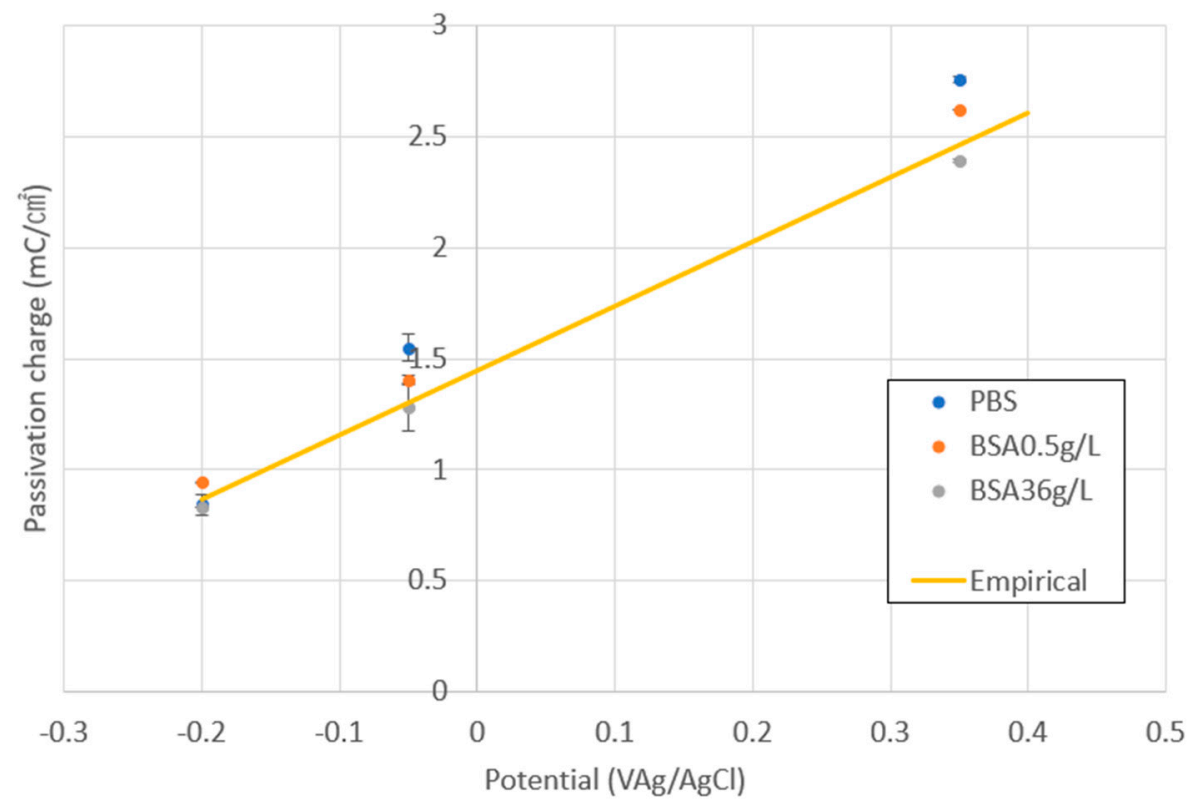

Figure 2. Passivation charge density as a function of applied potential in the different PBS and bovine serum albumin (BSA)-containing solutions. The straight line corresponds to the empirical equation relating $Q_{p}$ to the applied potential previously obtained by Bao et al. [21].

\subsection{Viscosity Measurements}

Shear rate and viscosity of all solutions were measured between $10 / \mathrm{s}$ and $100 / \mathrm{s}$. Water, PBS and BSA $0.5 \mathrm{~g} / \mathrm{L}$ solutions showed constant and low viscosity while BSA $36 \mathrm{~g} / \mathrm{L}$ solution showed higher viscosity and mild sheer-thinning behavior. Since the sheer rate in tribological contact is assumed to be very high, viscosity values at 100/s were selected and shown in Table 1.

Table 1. Viscosity values (in mPa s) of the studied solutions at 100/s.

\begin{tabular}{cc}
\hline PBS & 0.88 \\
\hline BSA $0.5 \mathrm{~g} / \mathrm{L}$ & 0.96 \\
\hline BSA $36 \mathrm{~g} / \mathrm{L}$ & 1.24 \\
\hline
\end{tabular}

\subsection{Tribocorrosion Tests}

\subsubsection{Friction and Current Measurements}

Tribocorrosion tests were carried out in PBS and BSA-containing solutions at different applied potentials. Figure 3 shows an example of the average values of the COF (Figure 3a) and the current (Figure $3 b$ ) during rubbing. After the first period of passivation, in which the current shows the typical exponential decrease, at the onset of rubbing, the current abruptly increases simultaneously to the $\mathrm{COF}$, remaining more of less constant until the end of the test. The increase in current is attributed to the mechanical removal of the passive film, depassivation, and the cyclic exposure of the metal surface 
to the solution followed by a fast repassivation. This process is repeated for each stroke, resulting in a wear-accelerated corrosion. The COF and the current decrease in the BSA $36 \mathrm{~g} / \mathrm{L}$ solution when compared to those in PBS and the BSA $0.5 \mathrm{~g} / \mathrm{L}$. The tribocorrosion response of the CoCrMo alloy in the low-BSA containing solution, BSA $0.5 \mathrm{~g} / \mathrm{L}$ is very similar to its response in PBS.
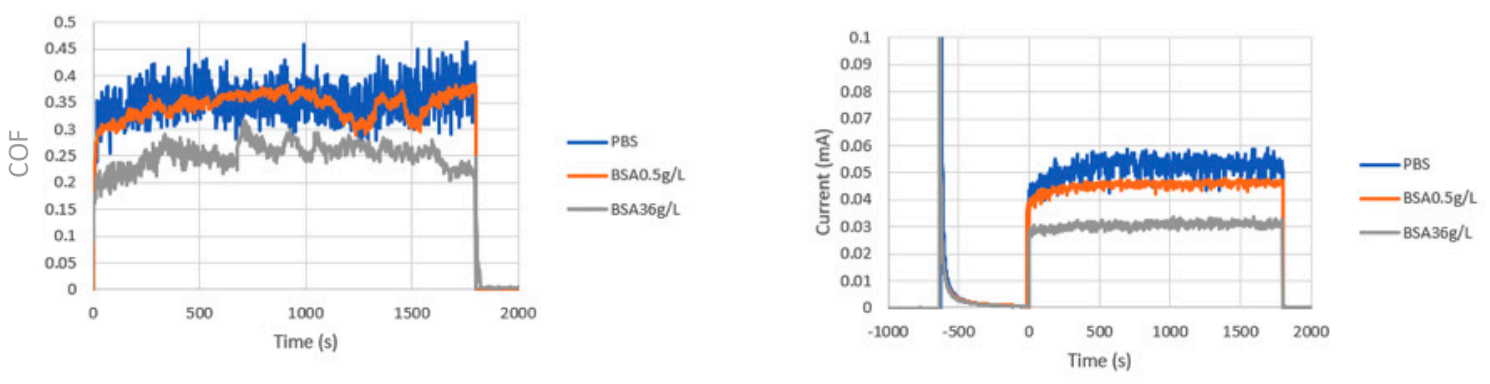

Figure 3. (a) Average values of coefficient of friction (COF) and (b) current versus time during the tribocorrosion tests of the CoCrMo at $0.35 \mathrm{~V}_{\mathrm{Ag} / \mathrm{AgCl}}$. Normal load 5.6N.

Table 2 summarizes the average values within a tribocorrosion test of the COF and current during sliding of the CoCrMo at different applied potentials in the different studied solutions. In the Table 2, the results of three independent repetitions of the tests carried out under the same conditions are shown. Only at intermediate passive potentials, $-0.05 \mathrm{~V}_{\mathrm{Ag} / \mathrm{AgCl}}$, six repetitions of the tests were carried out because in some of the tests a current and friction transition during sliding was observed. After several seconds of sliding, the current drop to low values simultaneously to a decrease in COF. These transitions were not systematically found. Figure 4 shows the evolution of the COF and the current of the CoCrMo during the tribocorrosion tests in all the studied solutions at $-0.05 \mathrm{~V} \mathrm{Ag} / \mathrm{AgCl}$ including two independent tests in BSA $36 \mathrm{~g} / \mathrm{L}$ (with and without the transition).

Table 2. Average value of the coefficient of friction (COF), average value of current, total, chemical and mechanical wear volumes at the end of the tribocorrosion tests at different applied potentials and different solutions.

\begin{tabular}{|c|c|c|c|c|c|c|}
\hline $\begin{array}{c}\text { Potential } \\
\left(\mathrm{V}_{\mathrm{Ag} / \mathrm{AgCl}}\right)\end{array}$ & Solution & $\mathrm{COF}$ & $\begin{array}{l}\text { Current }\left(I_{s}\right) \\
(m A)\end{array}$ & $\begin{array}{c}\text { Total Wear } \\
\left(\mathrm{V}_{\text {tot }}\right) \\
\left(10^{-3} \mathrm{~mm}^{3}\right)\end{array}$ & $\begin{array}{c}\text { Chemical Wear } \\
\left(V_{\text {chem }}\right) \\
\left(10^{-3} \mathrm{~mm}^{3}\right)\end{array}$ & $\begin{array}{c}\text { Mechanical } \\
\text { Wear }\left(V_{\text {mech }}\right) \\
\left(10^{-3} \mathrm{~mm}^{3}\right)\end{array}$ \\
\hline \multirow{9}{*}{-1} & \multirow{3}{*}{ PBS } & 0.34 & -0.279 & 0.111 & & 0.111 \\
\hline & & 0.35 & -0.351 & 0.0683 & & 0.0683 \\
\hline & & 0.31 & -0.371 & 0.116 & & 0.116 \\
\hline & \multirow{3}{*}{ BSA $0.5 \mathrm{~g} / \mathrm{L}$} & 0.12 & -0.425 & 0.0559 & & 0.0559 \\
\hline & & 0.13 & -0.436 & 0.0597 & & 0.0597 \\
\hline & & 0.13 & -0.349 & 0.063 & & 0.063 \\
\hline & \multirow{3}{*}{ BSA $36 \mathrm{~g} / \mathrm{L}$} & 0.18 & -0.962 & 0.140 & & 0.140 \\
\hline & & 0.19 & -0.544 & 0.141 & & 0.141 \\
\hline & & 0.17 & -0.964 & 0.107 & & 0.107 \\
\hline \multirow{6}{*}{-0.2} & \multirow{2}{*}{ PBS } & 0.39 & 0.297 & 2.71 & 1.60 & 1.11 \\
\hline & & 0.35 & 0.0296 & 2.72 & 1.60 & 1.12 \\
\hline & \multirow{2}{*}{ BSA $0.5 \mathrm{~g} / \mathrm{L}$} & 0.31 & 0.0280 & 2.85 & 1.51 & 1.34 \\
\hline & & 0.33 & 0.0284 & 2.92 & 1.53 & 1.39 \\
\hline & \multirow{2}{*}{ BSA $36 \mathrm{~g} / \mathrm{L}$} & 0.20 & 0.0140 & 0.986 & 0.76 & 0.226 \\
\hline & & 0.22 & 0.0143 & 1.01 & 0.77 & 0.230 \\
\hline
\end{tabular}


Table 2. Cont.

\begin{tabular}{|c|c|c|c|c|c|c|}
\hline $\begin{array}{c}\text { Potential } \\
\left(\mathrm{V}_{\mathrm{Ag} / \mathrm{AgCl}}\right)\end{array}$ & Solution & $\mathrm{COF}$ & $\begin{array}{l}\text { Current }\left(I_{s}\right) \\
(m A)\end{array}$ & $\begin{array}{c}\text { Total Wear } \\
\left(\mathrm{V}_{\text {tot }}\right) \\
\left(10^{-3} \mathrm{~mm}^{3}\right)\end{array}$ & $\begin{array}{c}\text { Chemical Wear } \\
\left(\mathrm{V}_{\text {chem }}\right) \\
\left(10^{-3} \mathrm{~mm}^{3}\right)\end{array}$ & $\begin{array}{c}\text { Mechanical } \\
\text { Wear }\left(V_{\text {mech }}\right) \\
\left(10^{-3} \mathrm{~mm}^{3}\right)\end{array}$ \\
\hline \multirow{12}{*}{-0.05} & \multirow{3}{*}{ PBS } & 0.38 & 0.0383 & 3.66 & 2.07 & 1.59 \\
\hline & & 0.37 & 0.0406 & 4.05 & 2.19 & 1.86 \\
\hline & & 0.29 & 0.0386 & 3.69 & 2.08 & 1.61 \\
\hline & \multirow{3}{*}{ BSA $0.5 \mathrm{~g} / \mathrm{L}$} & 0.35 & 0.0362 & 3.74 & 1.95 & 1.79 \\
\hline & & 0.35 & 0.0371 & 3.41 & 2.00 & 1.41 \\
\hline & & 0.31 & 0.0372 & 3.94 & 2.01 & 1.93 \\
\hline & \multirow{6}{*}{ BSA $36 \mathrm{~g} / \mathrm{L}$} & 0.27 & 0.0248 & 2.39 & 1.34 & 1.05 \\
\hline & & 0.30 & 0.0269 & 2.65 & 1.45 & 1.20 \\
\hline & & 0.18 & 0.00374 & 0.29 & 0.20 & 0.09 \\
\hline & & 0.20 & 0.00621 & 0.466 & 0.34 & 0.13 \\
\hline & & 0.17 & 0.00395 & 0.285 & 0.21 & 0.07 \\
\hline & & 0.17 & 0.00511 & 0.362 & 0.28 & 0.09 \\
\hline \multirow{9}{*}{0.35} & \multirow{3}{*}{ PBS } & 0.37 & 0.0469 & 4.05 & 2.53 & 1.52 \\
\hline & & 0.35 & 0.0513 & 4.51 & 2.77 & 1.74 \\
\hline & & 0.33 & 0.0501 & 4.53 & 2.70 & 1.83 \\
\hline & \multirow{3}{*}{ BSA $0.5 \mathrm{~g} / \mathrm{L}$} & 0.34 & 0.0453 & 4.42 & 2.44 & 1.98 \\
\hline & & 0.3 & 0.0487 & 4.07 & 2.63 & 1.44 \\
\hline & & 0.35 & 0.0453 & 4.27 & 2.44 & 1.83 \\
\hline & \multirow{3}{*}{ BSA $36 \mathrm{~g} / \mathrm{L}$} & 0.25 & 0.0306 & 3.11 & 1.65 & 1.46 \\
\hline & & 0.28 & 0.0317 & 3.02 & 1.71 & 1.31 \\
\hline & & 0.28 & 0.0301 & 2.72 & 1.62 & 1.10 \\
\hline
\end{tabular}
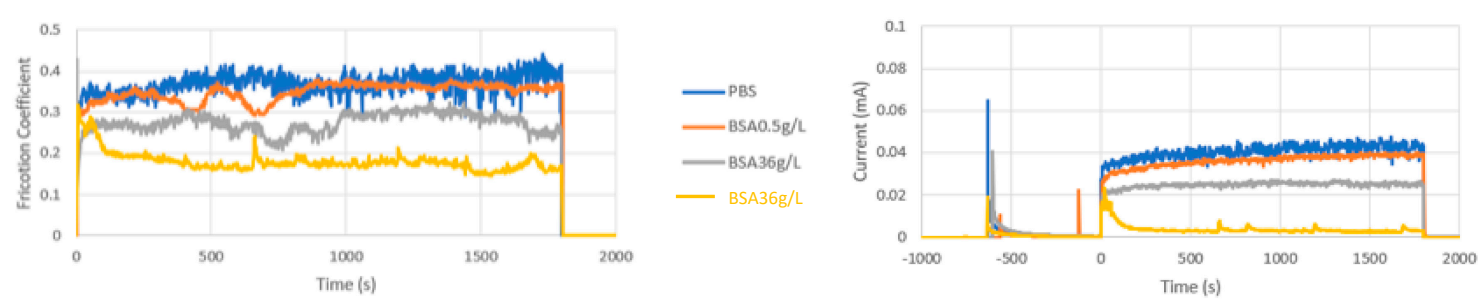

Figure 4. (a) Average values of $\mathrm{COF}$ and (b) current versus time during the tribocorrosion tests of the CoCrMo at $-0.05 \mathrm{~V}_{\mathrm{Ag} / \mathrm{AgCl}}$. Normal load $5.6 \mathrm{~N}$.

These kinds of transition in current and in friction, which have been previously observed, were attributed to a change in contact pressure as a consequence of the progressive growth of the wear track in the metal during sliding that changes the initial ball-on-flat configuration to a larger contact area ball-on-groove geometry $[6,8,22]$.

\subsubsection{Wear Quantification}

The total, chemical and mechanical wear is summarized in Table 2 . The total wear was quantified by $3 \mathrm{D}$ profilometry and the chemical wear volume $\left(\mathrm{V}_{\text {chem }}\right)$ was determined from the average current during sliding $\left(\mathrm{I}_{\mathrm{S}}\right)$ (Table 2) using Faraday's law as follows (Equation (1)).

$$
\mathrm{V}_{\text {chem }}=\frac{\mathrm{I}_{\mathrm{s}} \mathrm{tM}}{\mathrm{nF} \rho}
$$


where $\mathrm{M}$ is the atomic mass of the alloy, $\mathrm{n}$ is the charge number for the oxidation reaction (valence of oxidation was assumed 2.37), $\mathrm{F}$ is the Faraday constant $(96,485 \mathrm{C} / \mathrm{mol}), \rho$ is the density of the alloy equal to $8.3 \mathrm{~g} / \mathrm{cm}^{3}$ and $\mathrm{t}$ is the duration of rubbing, $1800 \mathrm{~s}$.

The mechanical wear was obtained by subtracting the chemical wear from the total wear volume. For those tests carried out under cathodic conditions, where there is negligible anodic dissolution, the whole volume of total wear was counted as mechanical wear.

Figure 5 shows an example of 3D images of the wear tracks after the tribocorrosion test carried out at $-0.05 \mathrm{~V}_{\mathrm{Ag} / \mathrm{AgCl}}$ when in the test was observed a transition (Figure $5 \mathrm{a}$ ) and without the transition (Figure 5b).

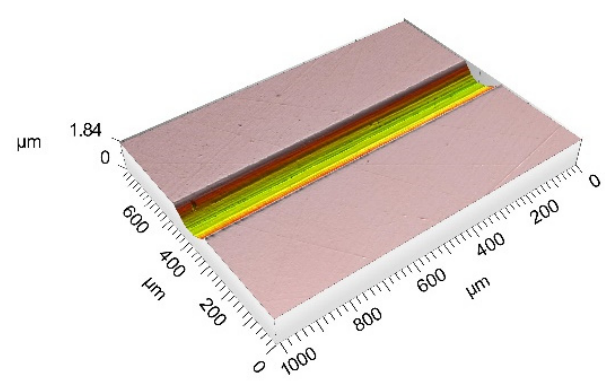

(a)

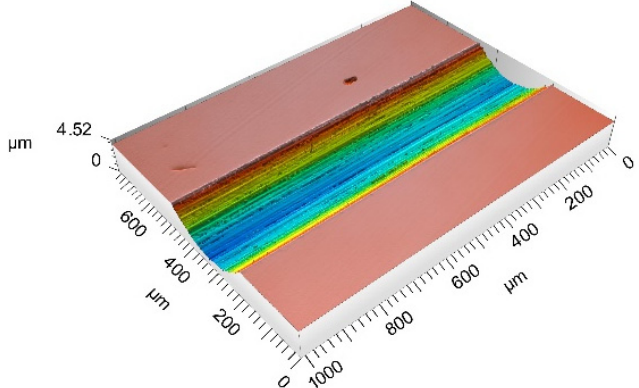

(b)

Figure 5. Three-dimensional laser profilometer image of the wear tracks after the tribocorrosion tests at $-0.05 \mathrm{~V}_{\mathrm{Ag} / \mathrm{AgCl}}$ when (a) COF and current transition was observed and (b) without the appearance of $\mathrm{COF}$ and current transition.

\subsubsection{Surface Morphology}

At the end of the tribocorrosion tests, the surfaces of the worn samples were analyzed by optical microscopy and SEM. Figure 6 shows the optical images of the obtained wear tracks at $-0.05 \mathrm{~V} \mathrm{Ag} / \mathrm{AgCl}$. Multiple grooves parallel to the sliding direction are observed in the PBS (Figure 6a) and BSA 0.5 g/L (Figure 6b) solutions, as well as in the BSA $36 \mathrm{~g} / \mathrm{L}$ (Figure 6c) solution when no transition was measured (high current and high COF). Similar patterns are observed in the wear tracks tested at the different applied passive potentials. However, when in the tribocorrosion test at $-0.05 \mathrm{~V} \mathrm{Ag} / \mathrm{AgCl}$ a $\mathrm{COF}$ and current transition occurs, the wear track is smoother (Figure 6d). Analogously, at an applied cathodic potential, $-1 \mathrm{~V}_{\mathrm{Ag} / \mathrm{AgCl}}$, the presence of $\mathrm{BSA}$ in the solution also suppresses the formation of those scratches.

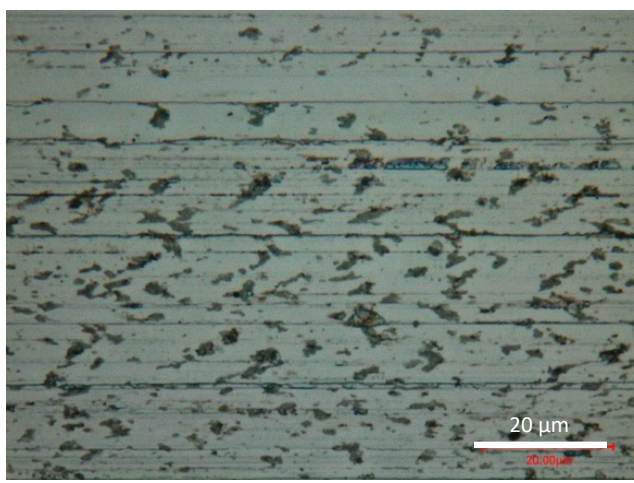

(a) PBS

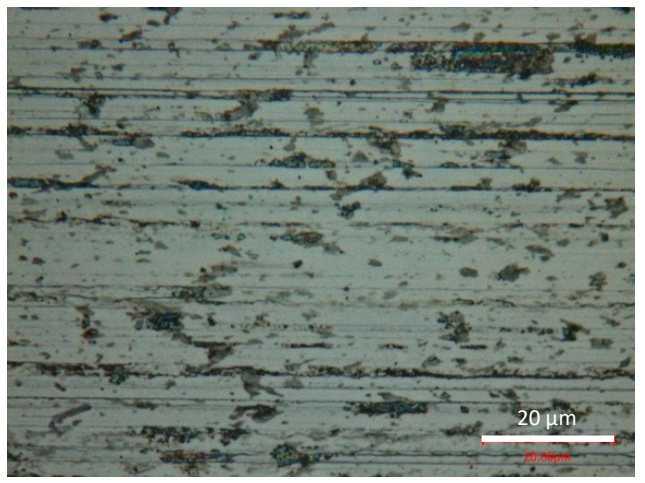

(b) BSA $0.5 \mathrm{~g} / \mathrm{L}$

Figure 6. Cont. 


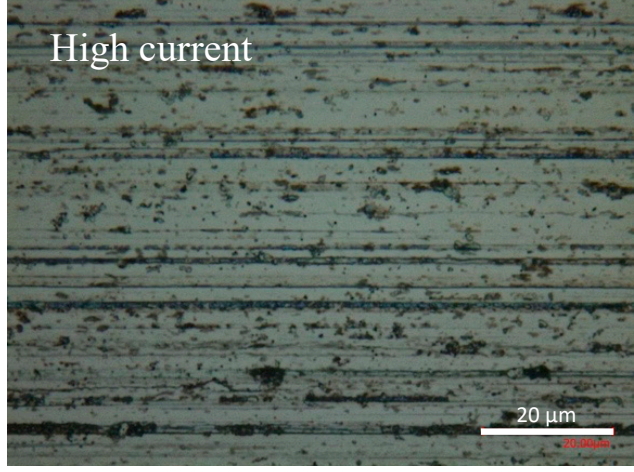

(c) BSA $36 \mathrm{~g} / \mathrm{L}$

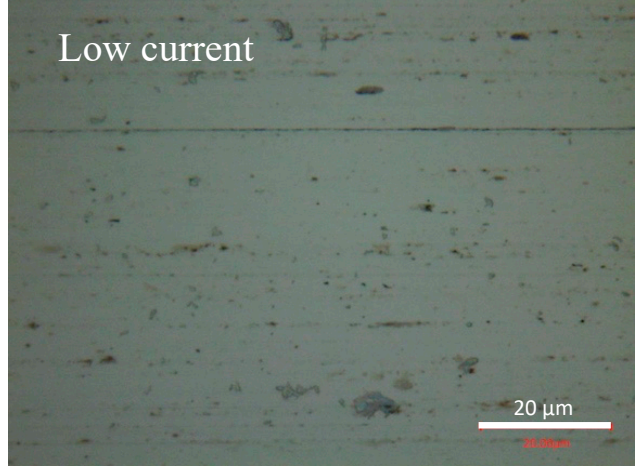

(d) BSA $36 \mathrm{~g} / \mathrm{L}$

Figure 6. Optical microscopy images of the wear tracks at the end of the tribocorrosion tests carried out at $-0.05 \mathrm{~V}_{\mathrm{Ag} / \mathrm{AgCl}}$ in (a) PBS, (b) BSA $0.5 \mathrm{~g} / \mathrm{L}$, (c) BSA $36 \mathrm{~g} / \mathrm{L}$ and (d) BSA $36 \mathrm{~g} / \mathrm{L}$ with COF and current transition.

SEM images of the wear tracks were also taken at the end of the tribocorrosion tests. Figure 7 shows one example of the appearance of the CoCrMo wear track tested in PBS at $0.35 \mathrm{~V} \mathrm{Ag} / \mathrm{AgCl}$. The surface appears quite smooth with some scratches along the sliding direction and wear debris in the nanometer range. This type of wear debris is typically observed when the material loss comes from the severely plastically deformed subsurface (nanocrystalline layer) and the detachment of nanograins. The presence of BSA in the electrolyte reduces the amount of wear debris and generates a featureless wear track.
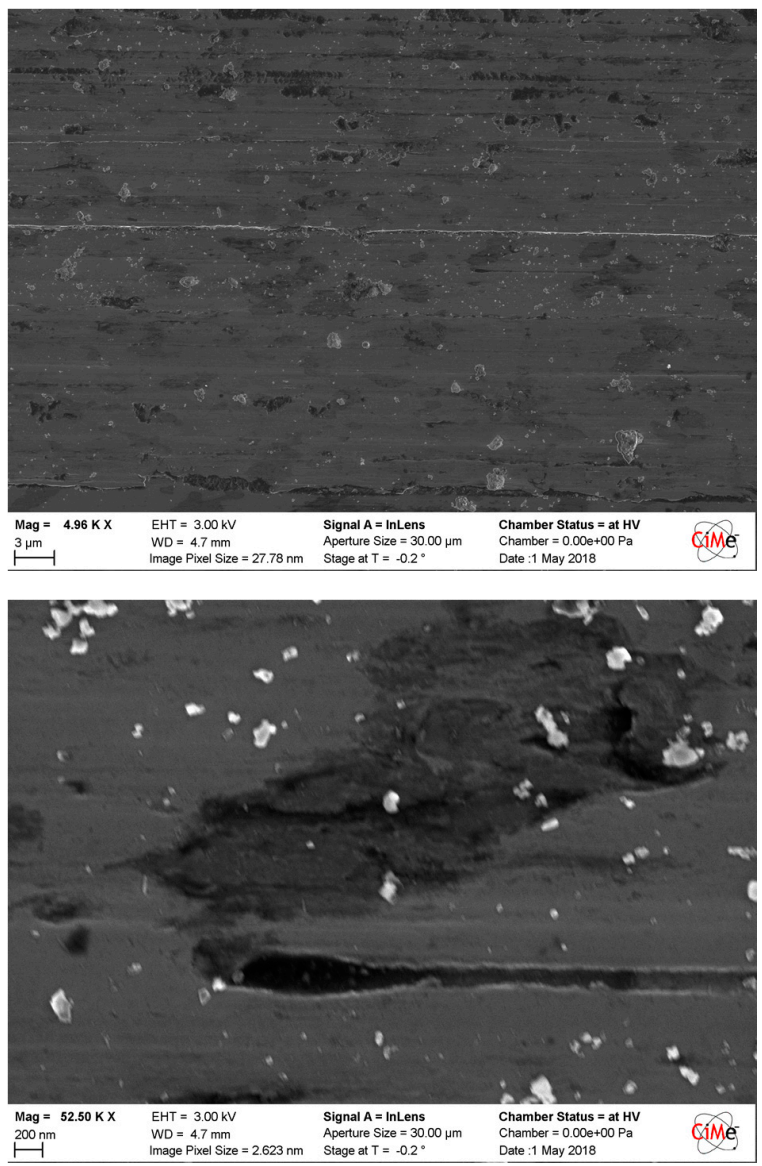

Figure 7. Scanning electron microscopy (SEM) image of the wear track of the CoCrMo sliding against an alumina ball in a PBS solution at $0.35 \mathrm{~V} \mathrm{Ag} / \mathrm{AgCl}$. 


\subsubsection{Surface Chemistry}

At the end of the tribocorrosion tests, AES spectra were acquired and $\mathrm{C}, \mathrm{O}, \mathrm{N}, \mathrm{Co}, \mathrm{Cr}$, and Mo peaks identified. AES depth profiles were then carried out inside and outside the wear tracks. The resulting AES depth profiles obtained after correction for the escape depth are shown in Figure 8.
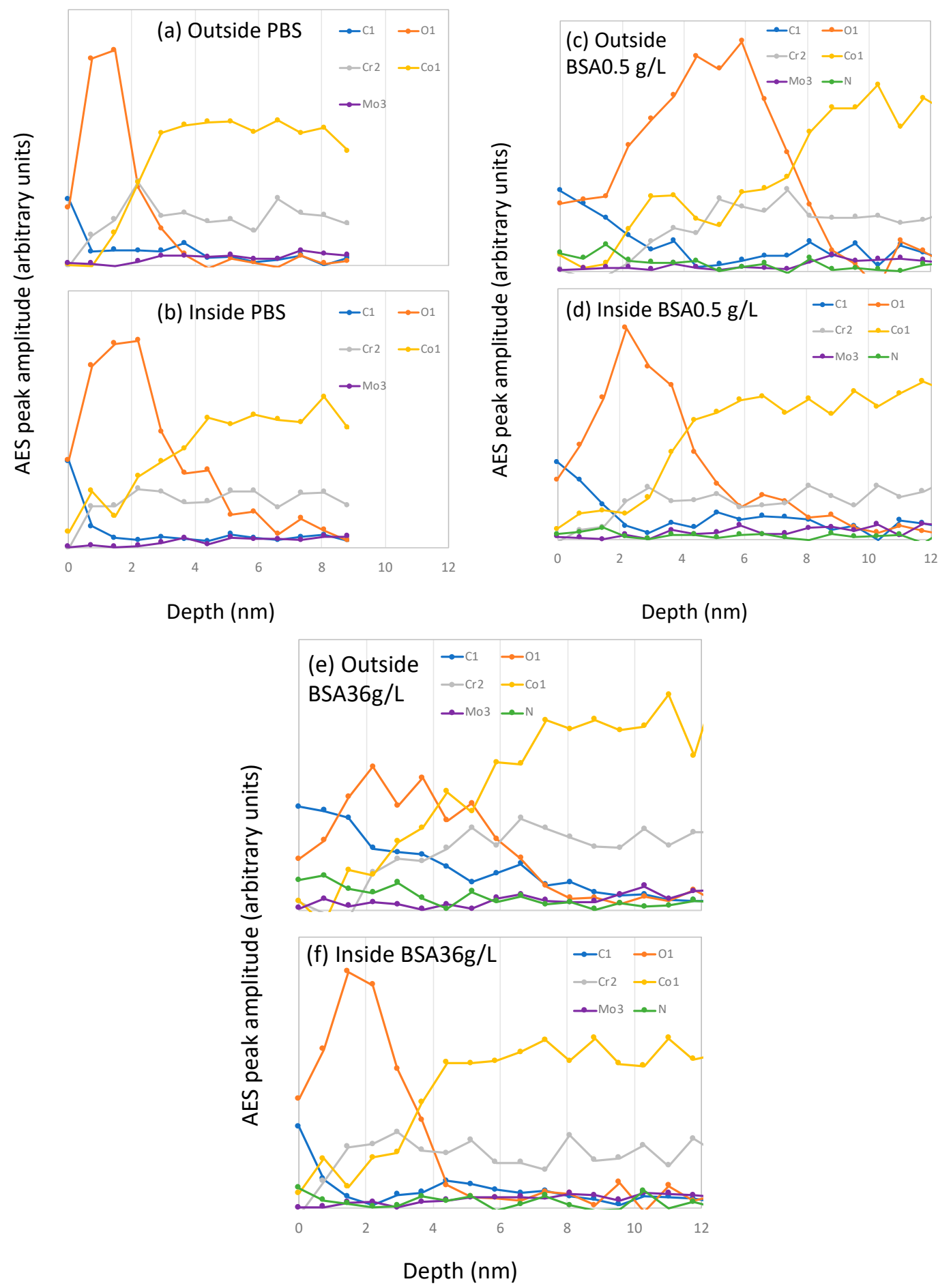

Figure 8. Auger electron spectroscopy (AES) sputter depth profiles after correction for the electron escape depth measured on samples inside and outside the wear tracks after the tribocorrosion tests carried out at $-0.2 \mathrm{~V}_{\mathrm{Ag} / \mathrm{AgCl}}$ in (a,b) PBS, (c,d) BSA $0.5 \mathrm{~g} / \mathrm{L}$ and $(\mathbf{e}, \mathbf{f}) \mathrm{BSA} 36 \mathrm{~g} / \mathrm{L}$ solutions. 
Outside the wear track, the $\mathrm{C}$ signals at the surface are stronger in the BSA-containing solutions, especially in the BSA $36 \mathrm{~g} / \mathrm{L}$ solution (Figure 8e), which also shows an intense N signal. Their intensity rapidly decreases with sputter time, indicating an adsorbed protein layer at the outermost part of the surface and the carbon contaminations taking place during the sample transfer to the AES chamber. The oxygen signal shows a maximum at certain sputter depths and it decreases again. These profiles, as already reported [18], correspond to a multilayer structure of the surface, with an outermost layer enriched in carbon, oxygen and nitrogen (no metal signal) and an underlying oxide layer mainly composed of chromium and some cobalt. The thickness of those carbon and oxide layers was determined by taking the depths at which the carbon and the oxygen signal is at $50 \%$ of its maximum amplitude, respectively. The obtained thickness values of both layers are summarized in Table 3. It is possible to observe that in the BSA-containing solutions both, the C-layer and the oxide film is thicker than in the PBS.

Table 3. C-layer and oxide thicknesses obtained from the AES profiles.

\begin{tabular}{ccc}
\hline Electrolyte & \multicolumn{2}{c}{ C-Layer (nm) } \\
& Inside the wear track & Outside the wear track \\
\hline PBS & 0.5 & 0.3 \\
\hline BSA 0.5 g/L & 1.2 & 2 \\
\hline BSA 36 g/L & 0.5 & 3 \\
\hline & \multicolumn{2}{c}{ Oxide film (nm) } \\
\hline PBS & Inside the wear track & Outside the wear track \\
\hline BSA 0.5 g/L & 2.8 & 1.5 \\
\hline BSA 36 g/L & 3 & 5 \\
\hline
\end{tabular}

Inside the wear tracks the depth profiles are solution dependent. In the PBS solution, the oxygen signal is broader compared to that obtained outside the wear track, while it is narrower in the BSA-containing solutions. The C-layer inside the wear track is also thinner than outside.

\section{Discussion}

\subsection{Effect of BSA on Wear and Friction at Passive Potentials}

Table 2 shows that wear and friction of the CoCrMo in the investigated solutions are affected by the combination of solution chemistry and electrochemical conditions (applied potential). This is not surprising since tribocorrosion results from the complex interaction of a variety phenomena such as lubrication, friction, depassivation/repassivation, and microstructural response and breakdown of the contacting materials. The mechanistic model proposed by Cao et al. [3] allows us to rationalize part of these phenomena and it will be therefore applied here. Equation (2) shows the tribocorrosion model:

$$
\begin{aligned}
& \mathrm{V}_{\text {tot }}=\mathrm{k}_{\text {mech }} \frac{(\mathrm{E} /)^{0.6556}}{\eta^{0.9685}} \times \frac{\left(\mathrm{F}_{\mathrm{n}}\right)^{1.3129}\left(\mathrm{v}_{\mathrm{s}}\right)^{0.0315}}{(\mathrm{R} /)^{1.1473} \mathrm{H}} \\
& +\mathrm{k}_{\text {chem }} \frac{\mathrm{MQ}_{\mathrm{p}}\left(\mathrm{E}^{\prime}\right)^{0.3278}}{\mathrm{nF \eta}^{0.4843}} \times \frac{\left(\mathrm{F}_{\mathrm{n}}\right)^{0.6565}\left(\mathrm{v}_{\mathrm{s}}\right)^{0.5158}}{\left(\mathrm{R}^{\prime}\right)^{0.5737} \mathrm{H}^{0.5}}
\end{aligned}
$$

where $V_{\text {tot }}$ is the total wear rate, which is the sum of mechanical wear rate $V_{\text {mech }}$ and chemical wear rate $V_{\text {chem }}, E^{\prime}$ is the effective Young's modulus, $F_{n}$ is the normal force, $v_{s}$ is the sliding velocity, $\eta$ is the viscosity of the solution, $\mathrm{R}^{\prime}$ is the effective radius of curvature, $\mathrm{H}$ is the surface hardness, $\mathrm{M}$ is the molecular mass, $Q_{p}$ is the passivation charge density, $n$ is the oxidation number, $F$ is the Faraday's constant, and $\rho$ is the density of the metal. The same parameters, except for the hardness, viscosity and passivation charge density already reported [3], were used for the calculation of the total wear. 
The microhardness was assumed to be $800 \mathrm{HV}$ a value that corresponds to the typical hardness found inside the wear tracks after tribocorrosion tests [23]. The viscosity values were taken from Table 1 and the passivation charge density was extracted at the different potentials from the empirical equation recently proposed by Bao [21] based on a systematic investigation of the passivation kinetics of a LC-CoCrMo alloy in a variety of solutions.

The calculated total wear rates in the three studied solutions at different passive potentials were compared to the experimental results in Figure 9.

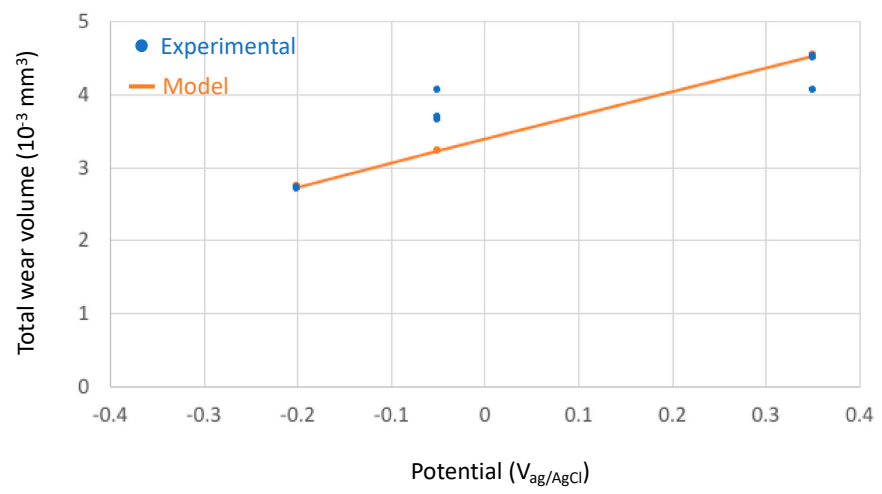

(a) PBS

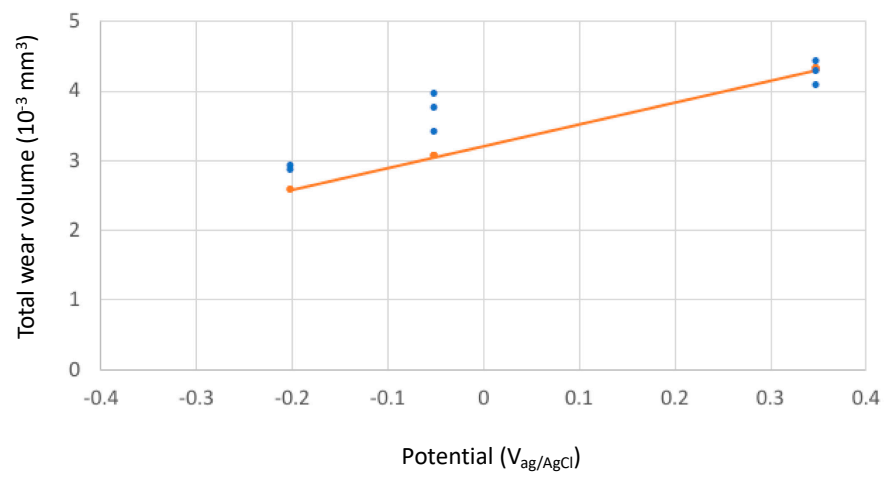

(b) BSA $0.5 \mathrm{~g} / \mathrm{L}$

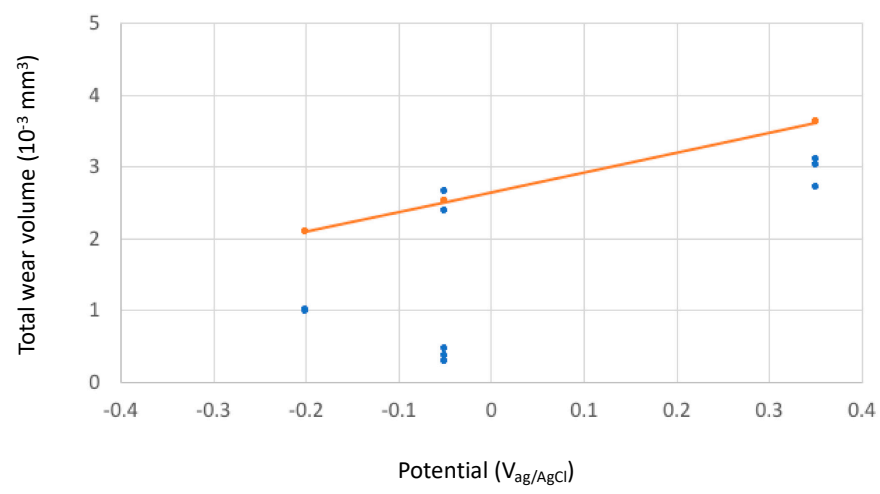

(c) BSA $36 \mathrm{~g} / \mathrm{L}$

Figure 9. Experimental (blue points) and theoretical (orange line) predicted total wear volumes after the tribocorrosion tests of the CoCrMo sliding against an alumina ball at different applied potential in the tested solutions (a) PBS, (b) BSA $0.5 \mathrm{~g} / \mathrm{L}$ and (c) BSA $36 \mathrm{~g} / \mathrm{L}$. 
The absolute wear values from the model predictions fits reasonably well to the experimental ones considering that the model constants $\left(\mathrm{k}_{\text {mech }}\right.$ and $\left.\mathrm{k}_{\mathrm{chem}}\right)$ were calibrated in sulphuric acid. The relative effect of BSA as described by the model corresponds well to the experimental observations: at low concentration, BSA only slightly reduces wear, while at high concentration, the wear reducing effect is more pronounced. According to the model, this effect is solely due to the change in the viscosity of the solution and therefore to its increase in hydrodynamic lubrication capability. This means that BSA can reduce wear even in the absence of adsorption or other surface chemical effects by simply changing the solution properties. However, quantitatively speaking, the model overestimates wear in the high concentrated BSA solution at $-0.2 \mathrm{~V} \mathrm{Ag} / \mathrm{AgCl}$ and, when transitions (current and friction) occur, at $-0.05 \mathrm{~V}_{\mathrm{Ag} / \mathrm{AgCl} \text {. }}$

The model predicts an increase in wear with potential because the passivation charge density shows the same trend with potential (Figure 2).

According to Wang [10], BSA generates a protective tribofilm that affects wear and subsurface deformation. However, the AES depths profiles in the wear tracks (Figure 8) do not show the presence of any significant carbonaceous layer. Moreover, the chemical composition of the wear tracks in both BSA solutions, 0.5 and $36 \mathrm{~g} / \mathrm{L}$, show the same signal intensity in $\mathrm{C}$ and $\mathrm{N}$ despite different wear behavior. Furthermore, the passive film has similar thickness independently of solution. Therefore, in the present case is difficult to attribute the lower wear observed at $-0.2 \mathrm{~V} \mathrm{Ag} / \mathrm{AgCl}$ in the BSA $36 \mathrm{~g} / \mathrm{L}$ solution to an evident surface chemical effect.

Interestingly, the occurrence of low wear coincides with friction values below 0.2 , while the rest of the tests exhibit higher COF, around 0.3. The two COF correspond to different stress fields in the material as already discussed by Wang et al. [10]. When the COF is around 0.3 the maximum shear stress is higher and located at the surface while at 0.2 that maximum is lower and below the surface. Thus, for COF 0.3, one expects larger surface strain and therefore higher wear, which is indeed observed in PBS and BSA $0.5 \mathrm{~g} / \mathrm{L}$ (Figure 9). Moreover, the AES depth profile at $-0.2 \mathrm{~V}_{\mathrm{Ag} / \mathrm{AgCl}}$ in PBS and BSA $0.5 \mathrm{~g} / \mathrm{L}$, exhibit an oxygen tail (Figure 8) possibly linked to a mechanical mixing occurring at the sliding metal surface. This oxygen tail is absent in the BSA $36 \mathrm{~g} / \mathrm{L}$ solution, probably because the lower COF implies lower surface shear stresses and limits or suppress mechanical mixing.

The reduction in COF in the BSA $36 \mathrm{~g} / \mathrm{L}$ solution is an expected effect as a consequence of the higher viscosity in that solution. Indeed, according to the Stribeck curves [24] the COF decreases with increasing viscosity in the mixed lubrication regime established in this type of contacts [3]. The surprising fact is that this effect seems to depend on the applied potential as shown in Table 2. At $0.35 \mathrm{~V}_{\mathrm{Ag} / \mathrm{AgCl}}$, BSA has a small effect on friction and at $-0.05 \mathrm{~V}_{\mathrm{Ag} / \mathrm{AgCl}}$ a significant effect appears only after a friction transition. The reason for that is not yet clear as friction as the energy dissipation phenomenon depends on a number of factors. For example, in the case of elasto-hydrodynamic aqueous lubricating films, the double layer properties affect the hydrodynamic film thickness and its viscosity [25,26]. It is known that the double layer changes with potential; for example, Munoz et al. [19] observed significant differences in the interface capacitance of CoCrMo surfaces passivated in PBS and PBS + BSA solutions. It is therefore possible that at a potential of $-0.2 \mathrm{~V} \mathrm{Ag} / \mathrm{AgCl}$ the enhancement of the apparent viscosity due to the double layer structure is sufficient to provide a significant fluid lubrication to the contact and thus to decrease friction. At the potential of $0.35 \mathrm{~V} \mathrm{Ag} / \mathrm{AgCl}$, this enhancement is weaker and friction is higher. At the intermediate potential of $-0.05 \mathrm{~V}_{\mathrm{Ag} / \mathrm{AgCl}}$, sufficient fluid lubrication occurs only after the contact pressure has been reduced as a consequence of run-in wear.

In the absence of quantitative data on the double layer characteristics at different potentials, as well as corresponding precise calculations of apparent film thickness and viscosity within the contact, the above considerations remain speculative. However, they clearly show that the effect of BSA on wear and friction can be explained by physical factors such as changes in viscosity and double layer structure without the need for BSA to form a two-dimensional adsorption film or a tribofilm within the contact. Indeed, in the present experiments, no tribofilm was observed, despite the significant effect of BSA at high concentrations on wear. 


\subsection{Effect of BSA on Wear and Friction at Cathodic Potential}

At applied cathodic potential, wear is much lower than at the passive ones. This was already observed in the literature for CoCrMo [23] and attributed to two factors: first, to the absence of wear accelerated corrosion, and second, to the lower mechanical wear due to the absence of the passive film that enhances subsurface strain accumulation. Interestingly, low wear is achieved also in the PBS solution despite the high COF. It means that high friction alone is not sufficient to generate high wear as observed here at applied passive potentials. This can be explained by the mild wear mechanism generally proposed for the tribocorrosion of CoCrMo. This mechanism consists of a sequence of phenomena. First the frictional stress field induces large strain accumulation into the surface. This leads to the formation by dynamic recrystallization of a nano-crystalline layer in the near surface zone of the contact. Indeed, this layer with grain dimensions ranging from 10 to $70 \mathrm{~nm}$ was systematically found in the tribocorrosion of CoCrMo alloys and stainless steels. Once formed, the deformation of the nano-crystalline layer can only proceed via rotation of the nano-grains $[27,28]$. With ongoing sliding, nanograins can reach a critical number of deformation cycles or a critical strain above which they get torn off and thus generate fatigue wear [27] or possibly ratcheting wear.

Note that the surface chemical effect may interfere in these mechanisms. Indeed, grains at the surface experience adsorption of molecules and/or oxidation by contact with water and the subsequent grain rotation brings the chemically modified surface deeper into the metal surface and thus weakens the inter-grain bonds and facilitate their ejection as wear particles. This grain boundary weakening mechanism was first proposed by Büscher [29] for the case of organic molecules or oxide species penetrating the surface of CoCrMo hip joints.

At the cathodic potential, the oxidation does not occur and therefore the nano-crystalline layer can withstand even large frictional stress without experiencing the high wear found at passive potentials. The effect of highly concentrated BSA at $-0.2 \mathrm{~V}_{\mathrm{Ag} / \mathrm{AgCl}}$ is consistent with this mild wear mechanism: despite the passive conditions, the low surface shear stress (low COF) limits the plastic deformation of the surface nanograins and thus their mechanical weakening by penetration of oxygen in the nanograin boundaries. This indicates that wear enhancement results from specific conditions of surface oxidation and stress field.

\subsection{Effect of BSA and Potential on Tribocorrosion of CoCrMo Alloys}

The above discussion has shown that the effect of BSA on the tribocorrosion of CoCrMo depends on concurrent factors linked to the hydrodynamic lubrication, stress field and the prevailing electrochemical conditions (e.g., presence or not of a passive film). The interplays of those factors can be assessed using existing theories, models and concepts. Accordingly, the effect of BSA, potential, normal load and velocity can be described with the following diagram (Figure 10).

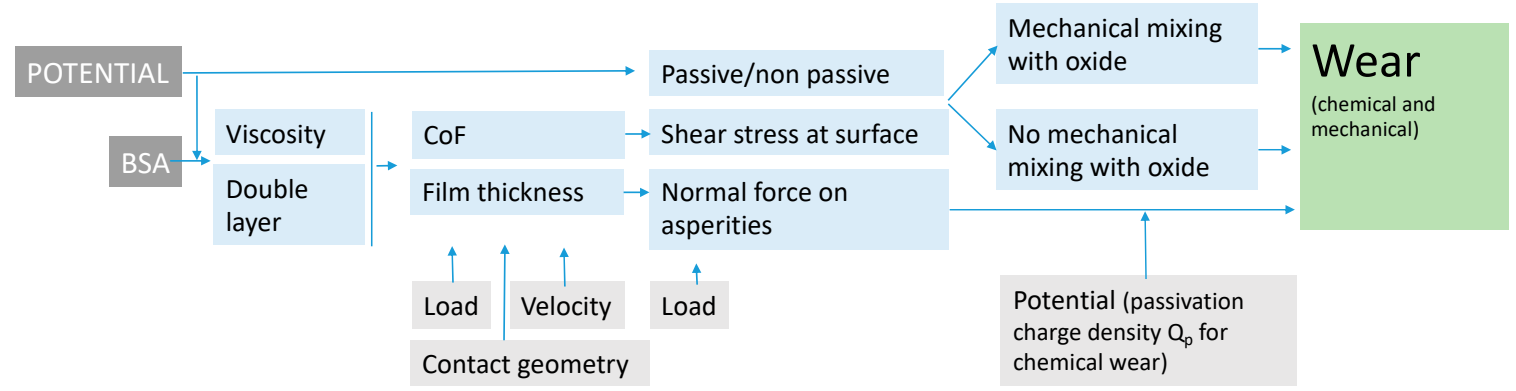

Figure 10. Block diagram showing the influence of BSA and the electrode potential on wear of CoCrMo alloy sliding against an alumina ball immersed in PBS solutions under mixed lubrication regime.

BSA modifies the viscosity of the solution as well as, depending on potential, the electrical double layer at the metal-solution interface. These factors control, together with the velocity, load and contact 
geometry, the extent of hydrodynamic lubrication and thus the hydrodynamic film thickness and the overall COF. The COF determines the shear stress acting at the sliding surface and thus the plastic behaviuor of the nanocrystalline layer generated at the surface. In the presence of a passive film and by sufficient shear stress, the plastic flow results in the mechanical mixing of oxide and metal, which reduces the mechanical resistance of the outermost nanocrystalline layer. When these two conditions are not simultaneously satisfied, no such weakening occurs. The film thickness determines the effective normal force acting on the asperities and, according to Cao's model (Equation (2)), mechanical and chemical wear. The potential determines the passivation charge density and as a consequence the chemical wear. The occurrence of mechanical mixing increases the severity of mechanical wear.

Although this diagram needs to be consolidated by more supporting scientific evidences, it allows for rationalizing some literature observations. Wang et al. [10] observed that albumin addition to PBS results in lower wear and lower friction and attributed this effect to the buildup of a tribofilm and to subsurface hardening. However, the viscosity increase due to the addition of albumin to PBS is supposed to facilitate hydrodynamic lubrication, a factor that additionally limits wear as indicated by the experimental and theoretical results obtained here (Figure 9).

The inflection point in the wear vs. load curve observed by Wimmer [12] coincides with minimum COF values close to 0.22 which, according to the mechanistic model proposed here, are expected to reduce wear severity by lowering the surface shear stress acting at the metal surface. This indeed explains the inflection. Wang et al. [10] and Namus et al. [11] are in apparent contradiction as they observed that thicker nano-crystalline layers leads to lower and higher wear rates, respectively. In our model, the wear is produced by the detachment of nano-grains from the outermost surface that is essentially controlled by the shear stress acting there and by mechanical mixing with non metallic species. This effect does not directly depend on the thickness of the nano-crystalline layer but on the mechanical properties of its outermost layer and on the surface chemical reactions.

\section{Conclusions}

This work has shown that under the present experimental conditions:

- Albumin does not affect the passivation kinetics of the CoCrMo alloy.

- Albumin reduces wear and friction.

- Albumin increases the viscosity of the solution and therefore enhances hydrodynamic effects which is the main mechanism by which albumin lowers wear, in agreement with Cao's tribocorrosion model.

- Moreover, albumin can lower the COF below a threshold of approximately 0.22 , but only under specific electrochemical conditions. As a consequence, the surface shear stress decreases and this limits the extent of mechanical mixing of oxide and metal and thus reduces wear.

- No significant albumin adsorption effects or tribofilm formation were observed in the wear tracks.

Author Contributions: Methodology and formal analysis, C.Y.; conceptualization and supervision, S.C.; writing-original draft preparation, A.I.M. and S.M.; Resources, S.M.; All authors have read and agreed to the published version of the manuscript.

Funding: This research received no external funding.

Acknowledgments: Choshun Yoneyama acknowledges financial support from the student exchange program of the University of Tokyo. Shoufan Cao acknowledges grant from China Scholarship Council. Thanks to Vance Ngyuen for the SEM analysis.

Conflicts of Interest: Declare conflicts of interest or state "The authors declare no conflict of interest." Authors must identify and declare any personal circumstances or interest that may be perceived as inappropriately influencing the representation or interpretation of reported research results. Any role of the funders in the design of the study; in the collection, analyses or interpretation of data; in the writing of the manuscript, or in the decision to publish the results must be declared in this section. If there is no role, please state "The funders had no role in 
the design of the study; in the collection, analyses, or interpretation of data; in the writing of the manuscript, or in the decision to publish the results".

\section{References}

1. Mischler, S. Sliding tribo-corrosion of passive metals: Mechanisms and modeling. In Tribo-Corrosion: Research, Testing, and Applications; Peter, B., Jean-Pierre, C., Dirk, D., Friedrich, F., Eds.; ASTM International: West Conshohocken, PA, USA, 2013.

2. Mischler, S.; Munoz, A.I. Wear of CoCrMo alloys used in metal-on-metal hip joints: A tribocorrosion appraisal. Wear 2013, 297, 1081-1094. [CrossRef]

3. Cao, S.; Maldonado, S.G.; Mischler, S. Tribocorrosion of pas- sive metals in the mixed lubrication regime: Theoretical model and application to metal-on-metal artificial hip joints. Wear 2015, 15, 55-63. [CrossRef]

4. Wimmer, W.A.; Sprecher, C.; Hauert, R.; Tager, G.; Fischer, A. Tribochemical re- action on metal-on-metal hip joint bearings a comparison between in-vitro and in-vivo results. Wear 2003, 255, 1007-1014. [CrossRef]

5. Wimmer, M.A.; Fischer, A.; Büscher, R.; Pourzal, R.; Sprecher, C.; Hauert, R.; Jacobs, J.J. Wear Mechanisms in Metal-on-Metal Bearings: The Importance of Tribochemical Reaction Layers. J. Orthop. Res. 2010, 28, 436-443. [CrossRef] [PubMed]

6. Yan, Y.; Neville, A.; Dowson, D. Tribo-corrosion properties of cobalt-based medical implant alloys in simulated biological environments. Wear 2007, 263, 1105-1111. [CrossRef]

7. Yan, Y.; Neville, A.; Dowson, D. Biotribocorrosion of CoCrMo orthopaedic implant materials-Assessing the formation and effect of the biofilm. Tribol. Int. 2007, 40, 1492-1499. [CrossRef]

8. Munoz, A.I.; Mischler, S. Effect of the environment on wear ranking and corrosion of biomedical CoCrMo alloys. J. Mater. Sci. Mater. Med. 2011, 22, 437-450. [CrossRef]

9. Mathew, M.T.; Jacobs, J.J.; Wimmer, M.A. Wear-Corrosion Synergism in a CoCrMo Hip Bearing Alloy Is Influenced by Proteins. Clin. Orthop. Relat. Res. 2012, 470, 3109-3117. [CrossRef]

10. Wang, Z.; Yan, Y.; Su, Y.; Qiao, L. Effect of proteins on the surface microstructure evolution of a CoCrMo alloy in bio-tribocorrosion processes. Colloids Surf. B Biointerfaces 2016, 145, 176-184. [CrossRef]

11. Namus, R.; Zeng, P.; Rainforth, W.M. Correlation of the wear transition in CoCrMo alloys with the formation of a nanocrystalline surface layer and a proteinaceous surface film. Wear 2017, 376-377, 223-231. [CrossRef]

12. Wimmer, M.A.; Laurent, M.P.; Mathew, M.T.; Nagelli, C.; Liao, Y.; Marks, L.D.; Jacobs, J.J.; Fischer, A. The effect of contact load on CoCrMo wear and the formation and retention of tribofilms. Wear 2015, 332-333, 643-649. [CrossRef] [PubMed]

13. Cao, S.; Mischler, S. Modeling tribocorrosion of passive metals-A review. Curr. Opin. Solid State Mater. Sci. 2018, 22, 127-141. [CrossRef]

14. Stojadinovic, J. Chemical-Mechanical Polishing of Tungsten: Electrochemical and Tribocorrosion Approach. Ph.D. Thesis, École Polytechnique Fédérale de Lausanne, Lausanne, Switzerland, 2009.

15. Hofmann, S.; Sanz, J.M. Thin Film and Depth Profile Analysis; Chapter 7; Springer: Berlin, Germany, 1984.

16. Mischler, S.; Mathieu, H.J.; Landolt, D. Investigation of a passive film on an Iron-Chromium alloy by AES and XPS. Surf. Interface Anal. 1988, 11, 182. [CrossRef]

17. Landolt, D.; Mischler, S.; Vogel, A.; Mathieu, H.J. Chloride ion effects on passive films on FeCr and FeCrMo studied by AES, XPS and SIMS. Corros. Sci. 1990, 31, 431.

18. Tanuma, S.; Powell, C.J.; Penn, D.R.; Tanuma, S.; Powell, C.J.; Penn, D.R. Calculation of electron inelastic mean free paths (IMFPs) VII. Reliability of the TPP-2M IMFP predictive equation. Surf. Interface Anal. 2003, 35, 165. [CrossRef]

19. Munoz, A.I.; Mischler, S. Interactive effects of albumin and phosphate ions on the corrosion of CoCrMo implant alloy. J. Electrochem. Soc. 2007, 154, C562-C570. [CrossRef]

20. Milošev, I.; Strehblow, H.H. The composition of the surface passive film formed on CoCrMo alloy in simulated physiological solution. Electrochim. Acta 2003, 48, 2767-2774. [CrossRef]

21. Bao, Y.; Kudo, T.; Cao, S.; Munoz, A.I.; Mischler, S. Passivation charge density of CoCrMo alloy in different aqueous solutions. J. Biol. Tribo-Corros. 2020, 6, 58. [CrossRef]

22. More, N.S.; Diomidis, N.; Paul, S.N.; Roy, M.; Mischler, S. Tribocorrosion behavior of $\mathbb{E} \leq$ titanium alloys in physiological solutions containing synovial components. Mater. Sci. Eng. C 2011, 31, 400-408. [CrossRef] 
23. Guadalupe, S.; Cao, S.; Cantoni, M.; Chitty, W.; Falcand, C.; Mischler, S. Applicability of a recently proposed tribocorrosion model to CoCralloys with different carbides content. Wear 2017, 366-377, 203-211. [CrossRef]

24. Hutchings, I.; Shipway, P. Tribology: Friction and Wear of Engineering Materials; Butterworth-Heinemann: London, UK, 2017.

25. Zuon, Q.; Huang, P.; Su, F. Theory analysis of asymmetrical electric double layer effects on thin film lubrication. Tribol. Int. 2012, 49, 67-74.

26. Chu, L.M.; Li, W.L.; Hsu, H.C.; Tsai, J.S. Effects of Electric Double Layer on Pure Squeeze Motion of Circular Contacts-An Elastohydrodynamic Lubrication Model. Adv. Mater. Res. 2012, 486, 497-502. [CrossRef]

27. Wimmer, M.A.; Loos, J.; Nassutt, R.; Heitkemper, M.; Fischer, A. The acting wear mechanisms on metal-on-metal hip joint bearings-In vitro results. Wear 2001, 250, 129-139. [CrossRef]

28. Fischer, A.; Weiss, S.; Wimmer, M.A. The tribological difference between biome- dical steels and CoCrMo-alloys. J. Mech. Behav. Biomed. Mater. 2012, 1, 50-62. [CrossRef] [PubMed]

29. Büscher, R.; Fischer, A. The pathways of dynamic recrystallization in all-metal hip joints. Wear 2005, 259, 887-897. [CrossRef]

(C) 2020 by the authors. Licensee MDPI, Basel, Switzerland. This article is an open access article distributed under the terms and conditions of the Creative Commons Attribution (CC BY) license (http://creativecommons.org/licenses/by/4.0/). 